\title{
Book Review: Thomas Berry: A Biography
}

\author{
Sam Mickey* \\ University of San Francisco, San Francisco, CA, United States
}

Keywords: religion, spirituality, cosmology, Thomas Berry, religion and ecology

\section{A Book Review on}

\section{Thomas Berry: A Biography}

Mary Evelyn Tucker, John Grim, Andrew Angyal (New York, NY: Columbia University Press), 2019, 360 pages, ISBN: 978-0231176989

Universities and other educational institutions are among the most influential sectors of society, and they are at a fork in the road. There are two options. On one hand, universities can continue reinforcing the status quo, whereby education trains humans to enter a destructive, extractive relationship with the environment. On the other hand, universities can be repurposed to facilitate a transition toward mutually beneficial relationships between humans and the Earth community. The former option is evident in the prevalence of university investments in fossil fuels, notwithstanding a relatively small number of universities that have partially or completely divested from fossil fuels. The former option is also evident in pedagogy that fails to treat ecological literacy and outdoor education as integral components of education; it is a pedagogy that sees the natural world as a series of objects, not as subjects with whom one might commune. The latter optionrepurposing universities for mutually beneficial human-Earth relations-is part of the Great Work of our time, as envisioned by Thomas Berry (1914-2009), a cultural historian and scholar of religion who developed an integrative perspective on humanity, Earth, and the universe. This "Great Work" is a matter of reorienting educational, political, economic, and religious institutions toward mutually enhancing human-Earth relations (p. 199). It means reorienting universities to a vision of the universe as a "communion of subjects," not as a "collection of objects" (p. 167). In other words, sustainability transitions at universities require recognition of the intrinsic, not merely instrumental, value of nature.

Berry's life and thought are exemplary guides for those who seek ways of reconnecting universities with the universe to empower a just and sustainable civilization. To put it quite simply, Berry's vision is about reconnecting the university to the universe. Berry is widely influential, both for the breadth of his intellectual pursuits and the depth of his spiritual sensitivity. Yet, although his life and work have touched environmentalists, poets, activists, scholars, and religious practitioners, there has been no thorough account of his biography, that is, until the publication of Thomas Berry: A Biography. This book is the collaborative effort of three authors. Two students of Berry-Mary Evelyn Tucker and John Grim-worked with the Andrew Angyal, who has written biographical accounts of other prominent figures oriented toward reintegrating humans with the natural world (e.g., Wendell Berry and Loren Eiseley). Following a brief introduction, the book is followed by 12 chapters and a short epilog.

The first eight chapters describe the trajectory of Berry's life. Growing up in his hometown of Greensboro, North Carolina, Berry developed a sense of independence, a concern for social justice, and an understanding of the challenges of religious diversity and inclusion. "Growing up Catholic in the South in the 1920s was not easy," since his values and customs "were not well-understood 
or appreciated" in the "overwhelmingly Protestant" context of Greensboro (p. 7). It was also in his youth that Berry began developing an affinity for the wild and a feeling of intimate belonging in nature. Berry describes a definitive encounter with the transformative power of nature when, at the age of 11 , he was enchanted by the beauty and wonder of a meadow (p. 16). Berry's connections to nature and faith continued developing, leading him into a religious life with the Passionist order of Catholic priests, graduate studies in cultural history, and formative journeys to China and Germany. He was continually building connections with the wisdom of the past, the living scholars of the present, and emerging scholars like Mary Evelyn Tucker and John Grim, who would go on to found and direct the Forum on Religion and Ecology.

Berry was committed to teaching, even when it seemed at odds with his Passionist order (p. 80). His teaching and ongoing studies expanded to include Christian and nonChristian traditions, including detailed engagements with Asian religions (e.g., Hinduism, Buddhism, Taoism, and Confucianism) and contemporary forms of spirituality. That commitment to education brought him to New York, where he taught at Fordham University and established the Riverdale Center for Religious Research. Increasingly, Berry sought to articulate the cosmological context of religions, viewing the world's wisdom traditions as expressions of the universe. Evolution, ecology, and the importance of responding to environmental crises became central to Berry's work (p. 100). Breaking new ground, Berry expressed these topics in writings, which were collected and published in influential books like The Dream of the Earth (1988), The Great Work (1999), The Sacred Universe (2009), and others (p. 116). Berry developed a profound partnership with the cosmologist Brian Thomas Swimme, with whom he would write a book that presents an integrative narrative of the evolving universe and the place of humans therein-The Universe Story (1992). For the rest of his life, Berry continued sharing his vision with others, influencing a wide array of people, and inspiring others to take up the Great Work of our time.

Following the eight biographical chapters of this book, a brief interlude provides summary reflections before proceeding to the final four chapters, which elaborate on the details of Berry's ideas. The ninth chapter cover Berry's understanding of time and evolutionary processes in terms of narrative structures. Chapter 10 discusses the ideas of the French Jesuit paleontologist and theologian Pierre Teilhard de Chardin (1881-1955), whose evolutionary conception of the intertwining of spirit and matter was deeply influential for Berry's vision. The eleventh chapter elaborates on Berry's engagement with Asian religions, specifically his appreciation for the Confucian understanding of the complex unity of humanity, Earth, and the cosmos. The final chapter outlines the influence of the "cosmovisions" of Indigenous peoples (p. 240).

On its own terms, this book is a remarkable representation of Berry's life, thought, and influence. However, in terms of the specific challenges of reconnecting universities to their ecological and cosmic contexts, specific details are lacking. It is understandable that a biography would not address the particularities involved with the pedagogical, curricular, and administrative involved with repurposing universities for sustainability. The reader must look elsewhere for those details. Furthermore, the reader must look elsewhere for any sustained critique of Berry's integral vision. While the authors note that Berry is a historically situated thinker who, like anybody, has a limited perspective shaped by their unique context, the authors do not take him to task for any of his theoretical positions of philosophical assumptions.

Between the biographical writing skills of Angyal and the intimate knowledge of Berry shared by Tucker and Grim, this book is masterfully composed. Since Berry passed in 2009, one could say that this book is long overdue, yet it seems more relevant now than ever, as intensifying ecological crises are waking many humans up to the Great Work of this historical moment and the need for a new story that can empower communion between the diversity of the human community, the Earth community, and indeed, the evolving universe. Berry was a "thinker always moving toward becoming a cosmic person" (p. 263). Particularly relevant to the challenge of repurposing universities for sustainability, this biography provides an inspiring model of life and thought for the kind of integrative education required to meet this moment, an education that engages multiple perspectives across cultures to unite religion and ecology, bringing into the university a diverse variety of spiritual and scientific ways of knowing the universe. "Sensitized to such guidance from the very structure and functioning of the universe, we can have confidence in the future that awaits the human venture" (p. 264).

\section{AUTHOR CONTRIBUTIONS}

The author of this book review is SM.

Conflict of Interest: The author declares that the research was conducted in the absence of any commercial or financial relationships that could be construed as a potential conflict of interest.

Copyright (๑) 2021 Mickey. This is an open-access article distributed under the terms of the Creative Commons Attribution License (CC BY). The use, distribution or reproduction in other forums is permitted, provided the original author(s) and the copyright owner(s) are credited and that the original publication in this journal is cited, in accordance with accepted academic practice. No use, distribution or reproduction is permitted which does not comply with these terms. 